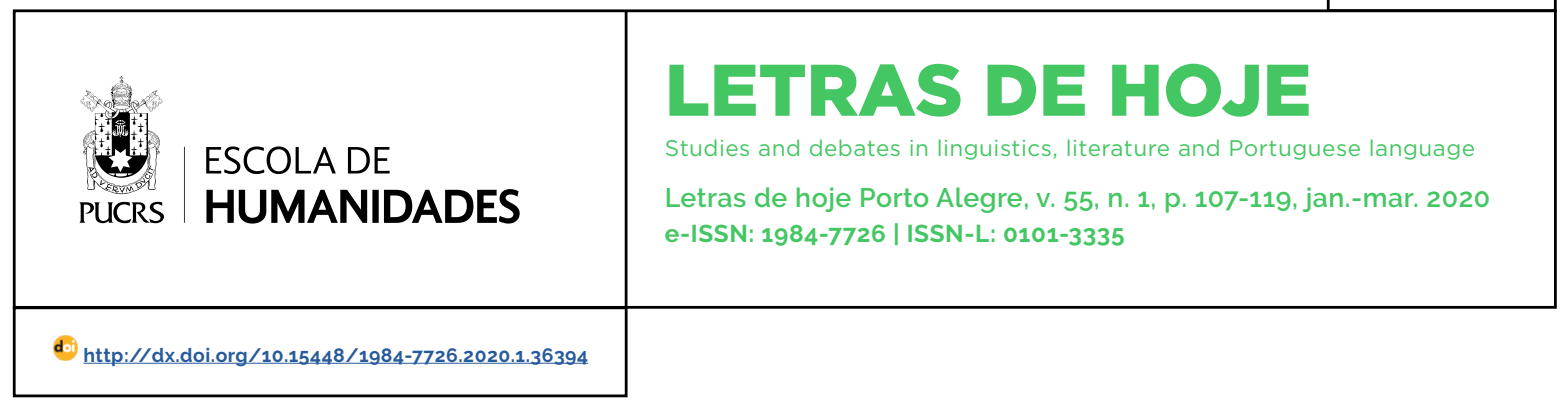

\title{
Arquitetura in absentia no conto "Catedral", de Raymond Carver
}

\author{
Architecture in absentia: "Cathedral", by Raymond Carver \\ Arquitectura in absentia en el cuento "Catedral", de Raymond Carver
}

\author{
Miriam de Paiva Vieira ${ }^{1}$ \\ orcid.org/0000-0001-9851-0217 \\ miriamvieira@ufsj.edu.br
}

Recebido em: 12 nov. 2019 Aprovado em: 14 nov. 2019 . Publicado em: 14 abr. 2020.

\section{(c) (i)}

Artigo está licenciado sob forma de uma licença Creative Commons Atribuição 4.0 Internacional.
Resumo: A écfrase, tanto como ferramenta retórica da antiguidade quanto como recurso literário, é um procedimento (inter)midiático que atua no cruzar de fronteiras entre a literatura e outras formas de manifestações artísticas, tais como pintura, escultura e arquitetura. Ao fazer uma edificação presente em uma obra literária, a écfrase é capaz de elucidar não somente espaços construidos familiares, mas também lugares nunca vistos antes. Esse é o caso de "Catedral" (1980), do autor estadunidense Raymond Carver, em que o simbolismo dos efeitos provocados pela tentativa, por parte do narrador ateu, de fazer o personagem cego ver uma obra arquitetônica religiosa, televisionada em um documentário, por meio de um desenho costuma ser lido como uma virada no pessimismo mordaz da obra do autor. Assim sendo, a partir da noção de écfrase como fenômeno midiático (VIEIRA, 2017) e do estudo de transferência de características entre mídias (ELLESTRÖM, 2010, 2014, 2017), o objetivo desse ensaio é discutir de que maneira a mídia arquitetura se faz presente (ou não) no conto "Catedral". Palavras-chave: Écfrase. Intermidialidade. Arquitetura. Literatura comparada. Raymond Carver.

Abstract: The notion of ekphrasis, either understood as a rhetorical device from antiquity or as a literary tool, is a (inter) medial procedure that enables the crossing of borders between literature and other forms of art, such as painting, sculpture and architecture. By making an absent edifice present in a literary work, ekphrasis is able to elucidate not only familiar built environments, but also places never seen before. As it is the case of the short story "Cathedral" (1980), by Raymond Carver. The symbolism aroused by effort of the atheist narrator to make a blind character see a religious architectural construction streamed by a television documentary through a drawing has been read as a turning point in the author's bitter pessimism. Departing from the notion of architecture as a medial phenomenon (VIEIRA, 2017) along with the study on the transfer of medial characteristics among dissimilar media (ELLESTRÖM, 2010, 2014, 2017), the aim of this paper is to discuss how the medium architecture is made present (or not) in the short story "Cathedral". Keywords: Ekphrasis. Intermediality. Architecture. Comparative literature. Raymond Carver.

Resumen: La écfrasis, tanto como herramienta retórica de la antigüedad como recurso literario, es un procedimiento (inter) mediático que actúa en el cruce de fronteras entre la literatura y otras formas de manifestaciones artísticas, como la pintura, la escultura y la arquitectura. Al hacer que una edificación esté presente en una obra literaria, la écfrasis puede dilucidar no solo construcciones familiares, sino también lugares nunca antes vistos. Es el caso del cuento "Catedral" (1980), de Raymond Carver, en lo que el simbolismo de los efectos causados por el intento del narrador ateo de hacer que el personaje ciego vea una obra arquitectónica religiosa, televisada en un documental, por medio de un dibujo, a menudo se lee como un punto de inflexión en el mordaz pesimismo de la obra del autor. Por lo tanto, con base en la noción de écfrasis como un fenómeno mediático (VIEIRA, 2017) y en el estudio de la transferencia de caracteristicas entre los medios (ELLESTRÖM, 2010, 2014, 2017), el objetivo de este ensayo es discutir cómo el medio arquitectura se hace presente (o no) en el cuento "Catedral".

Palabras clave: Écfrasis. Intermedialidad. Arquitectura. Literatura comparada. Raymond Carver. 
Qual é a amplitude da literatura quando a palavra literária se espalha pelas artes? E quando as artes e as mídias fazem o movimento inverso e se fazem presentes na literatura? De modo a pensar o fenômeno midiático écfrase como operador teórico que amplia o espaço da literatura, o objetivo deste artigo é discutir de que maneira a mídia arquitetura se faz presente (ou não) no conto "Catedral", de autoria do estadunidense Raymond Carver.

Conhecido como um dos representantes do movimento Dirty Realism, Carver e a sua escrita minimalista, herdada de Hemingway, retrata com ironia, que beira o cinismo, o dia a dia enfadonho e sem glamour do proletariado de seu país. Seus personagens são, em geral, blue collars², ou seja, trabalhadores braçais. As consequências do alcoolismo que o autor enfrentou ao longo de sua curta vida - ele faleceu com apenas 50 anos - renderam-lhe enredos mordazes e pessimistas. De acordo com sua fortuna crítica, o conto "Catedral", escrito após uma fase de recuperação bem-sucedida, é tido como uma virada otimista em busca da religiosidade. No entanto, o foco desse ensaio é o trecho de "Catedral" que trata de catedrais (CARVER, 2010, p. 633-635).

Publicado e situado no início da década de 1980, o conto é narrado em primeira pessoa por um típico personagem de Carver, que após um longo dia de trabalho, só pensa em sentar-se à frente da TV e descansar tomando uma cerveja. Mas nesse dia sua esposa havia convidado Richard, seu amigo cego para jantar. Após a sobremesa, os três acomodam-se na sala para continuarem seus drinks. A esposa e Richard conversam animadamente sobre um passado que o narrador não fez parte. Incomodado, ele liga a TV. A esposa repreende o marido pela indelicadeza. Logo em seguida ela deixa a sala, os dois homens e a televisão ligada. O narrador oferece um cigarro de maconha ao convidado, que aceita. Os dois bebem e fumam ao som da previsão do tempo e da cobertura esportiva. Ao final do noticiário, o narrador troca os canais da TV em busca de outro programa e, na falta de alternativas, escolhe um documentário sobre catedrais. Conforme sugerido por Peter Middleton (1998), "The Great Thaw", segundo episódio da série Civilisation (1969) da rede de televisão inglesa $\mathrm{BBC}$, narrado pelo historiador britânico Kenneth Clark:
A tevê mostrou uma catedral. Depois veio uma tomada longa e lenta de ou- tra catedral. Por fim, surgiu a imagem daquela catedral famosa em Paris com seus arcobotantes suspensos e suas tor- res que subiam até as nuvens. A câmera recuou para mostrar o conjunto de ca- tedrais se erguendo contra o horizonte. O inglês que narrava aquele negócio de vez em quando ficava calado e simples- mente deixava a câmera passear sobre as catedrais. Ou então a câmera se voltava para paisagens rurais, homens andando atrás de bois em campos de lavoura. Esperei mais que pude. Ai achei que eu precisava falar alguma coisa (CARVER, 2010, p. 633, grifo nosso).

Esse incômodo criado pelo silêncio entre os comentários de Clark é sanado por tentativas frustradas do narrador em verbalizar o que vê na tela da televisão. O simbolismo dos efeitos provocados por tal esforço, que culmina no final epifânico em que os dois personagens desenham juntos uma catedral e, com os olhos cerrados, o narrador afirma estar sentindo uma sensação incrivel, é o que costuma ser lido como uma virada no pessimismo do autor por sua fortuna crítica. Entretanto, a partir dos estudos sobre (inter)midialidade(s), Jørgen Bruhn argumenta que a celebrada epifania não é uma revelação divina, e sim a constatação da mídia fobia de um chovinista (BRUHN, 2016, p. 61-79). Para o autor, o trecho em questão trata da falha de uma transformação midiática, ou uma "écfrase mal-sucedida" (BRUHN, 2016, p. 70). Stephanie Glaser, estudiosa da representação da arquitetura gótica na literatura, também não se atém aos possiveis significados religiosos para demonstrar como a descrição da catedral gótica é capaz de propulsionar a narrativa do conto. A autora lê o trecho analisado como uma "descrição verbal"

\footnotetext{
2 Ao contrário dos white collars, que trabalham em escritórios e não usam uniforme, o termo blue collar vem da cor dos uniformes usados por assalariados que fazem trabalho manual, como mecânicos, mineiros, estivadores (grifos nossos, tradução nossa) Disponivel em: https://www.dictionary.com/browse/blue--collar?s=t. Acesso em: 4 dez. 2019.
} 
que "amplia e cria a narrativa". Para ela, "Catedral" apresenta um exemplo "extraordinário de descrição arquitetônica que propulsiona a narrativa" (2017, p. 13-15). Enquanto Bruhn usa o termo écfrase, Glaser prefere descrição verbal arquitetônica.

O recurso retórico écfrase é, de certa forma, uma descrição verbal, mas nem toda descrição é uma écfrase. A partir do sentido moderno difundido no século $X X$, a écfrase acontece quando, em um processo mental, a evocação de uma imagem visual é desencadeada a partir de sua verbalização, por intermédio de um texto lido ou escutado. A écfrase, tanto como ferramenta retórica da antiguidade quanto como fenômeno midiático contemporâneo, é um procedimento que atua no cruzar de fronteiras entre a literatura e outras formas de manifestação artística, tais como pintura, escultura, arquitetura. Ao fazer uma catedral presente em um conto, a écfrase arquitetônica tem a capacidade de elucidar não somente espaços construidos familiares, mas também lugares nunca antes vistos. Como fenômeno midiático, a écfrase pode ser entendida como um procedimento de transformação entre mídias diferentes ou, nas palavras de Lars Elleström, transmidiação, uma vez que, a partir de uma provocação verbal com impacto emocional, irá desencadear uma resposta imaginativa visual na mente do receptor.

Em seu modelo para estudo de transferência de caracteristicas de mídias (2010, 2014, 2017), Elleström combina caracteristicas semióticas - que englobam aspectos icônicos, indexicais e simbólicos - e não semióticas - que dizem respeito aos fundamentos da midiação. Para ele, as características não semióticas envolvem tanto as modalidades material, sensorial e espaçotemporal, quanto seus respectivos aspectos qualificadores: contextual e operacional.

A modalidade semiótica trata do sistema de significação e representação da mídia. Um tema bastante investigado dentro da modalidade semiótica é o da similaridade estrutural - ou iconicidade diagramática, de acordo com Peirce - no caso, entre o estilo da obra arquitetônica e o texto escrito. Bruhn chama atenção para o modo como Carver cita Hemingway ao comparar prosa a arquitetura e palavras a pedras construtivas. Para Hemingway, "prosa é arquitetura, e não decoração de interiores, e o barroco já passou"3 (1999a, p. 153, tradução nossa; 1999b, p. 72). Richard, por ser cego, não tem "uma boa ideia do que é uma catedral" (CARVER, 2010, p. 634), já para narrador, elas "não têm nenhum significado especial" (CARVER, 2010, p. 635). Ou seja, a estética gótica não faz parte do conhecimento prévio de nenhum dos dois personagens e, como sugerido por Hemingway, muito menos contamina a narrativa minimalista de Carver.

A modalidade material, diz respeito à materialidade física, concreta, da mídia em questão e à relação mental envolvida no processo de transmidiação. Portanto, o produto final é composto por diferentes materiais, tais como mármore e pedra. Mas, sendo a arquitetura um processo que envolve várias etapas, a materialidade acontecerá também dentro da mente dos envolvidos desde o momento em que alguém decide construir algo até o momento em que a edificação está pronta para ser utilizada. A comunicação acerca da futura edificação só será bem-sucedida quando uma imagem mental comum puder ser incitada, que é o princípio básico da écfrase, como nesse trecho em que a catedral Notre Dame de Paris é evocada:
A tevê mostrou uma catedral. Depois veio uma tomada longa e lenta de ou- tra catedral. Por fim, surgiu a imagem daquela catedral famosa em Paris com seus arcobotantes suspensos e suas torres que subiam até as nuvens. A câ- mera recuou para mostrar o conjunto de catedrais se erguendo contra o horizon- te (CARVER, 2010, p. 633, grifo nosso).

Ainda sobre a modalidade material, o narrador menciona alguns elementos decorativos: gárgulas e estátuas esculpidas em forma de

\footnotetext{
3 Do original: Prose is architecture, not interior decoration, and the Baroque is over. Em acordo com a teoria do iceberg proposta por Hemingway, sem deixar de tocar em temas profundos, Carver preza mais o processo que leva a uma escrita concisa e enxuta, do que ao rebuscamento barroco do texto.
} 
demônios, de senhores e de senhoras, assim como elementos construtivos característicos do estilo arquitetônico, como os arcobotantes, cuja forma o narrador compara com viadutos:

"Agora estão mostrando a parte externa da catedral. As gárgulas. Umas estátuas pequenas esculpidas para parecerem monstros. As gárgulas. Acho que agora estão na Itália. Tem pinturas nas paredes dessa igreja".

"São afrescos, meu camarada?', perguntou e tomou um gole do seu drinque. Estendi a mão para alcançar meu copo. Mas estava vazio. Tentei me lembrar do que eu podia. 'Está me perguntando se são afrescos?', falei. 'Boa pergunta. "Não sei'".

A (mal-sucedida) écfrase continua:

\begin{abstract}
"Antes de mais nada, elas são muito altas". Fiquei olhando em volta da sala, em busca de alguma ideia. "Elas sobem muito alto. Vão subindo, subindo a vida toda. Na direção do céu. Algumas são tão grandes que precisam de escoras. Que ajudem a sustentar, sabe. Essas escoras são chamadas de arcobotantes. Para mim, lembram os viadutos, não sei por quê. Mas talvez você também não saiba como são viadutos, não é? Às vezes as catedrais têm também uns demônios, umas coisas assim esculpidas na frente. Às vezes uns senhores e umas senhoras. Não me pergunte por quê", falei. (CARVER, 2010, p. 633-634. grifo nosso).
\end{abstract}

Os termos gárgula e arcobotante são bastante técnicos e destacam-se na fala coloquial e simplista do protagonista, indicando que, provavelmente, os termos foram ditos pelo narrador do documentário, ouvidos e repetidos pelo narrador do conto:

Sei que sua construção exigia centenas de operários e que levavam cinquenta ou cem anos para ficar prontas", disse. "Acabei de ouvir o homem falar isso, claro. Sei que diversas gerações das mesmas familias trabalhavam numa catedral. Ouvi o homem dizer isso também. Os homens que iniciavam a vida tralhando numa catedral morriam sem ver seu trabalho concluido.

A modalidade espaço-temporal é provavelmente o tema mais investigado por parte tanto de arquitetos como de estudiosos da literatura. O processo arquitetônico como um todo ocupa definitivamente diferentes tipos de espaços que, por sua vez, não podem ser dissociados do tempo.

Tentei achar mais alguma coisa para dizer. "Elas são grandes mesmo", falei. "São pesadas. São feitas de pedra. De mármore também, às vezes. Antigamente. na época em que os homens construiam catedrais, eles queriam ficar perto de Deus. Antigamente, Deus era uma parte importante da vida de todo mundo. Dá para ver isso pela construção das catedrais. Desculpe", falei, 'mas parece que isso é o máximo que consigo fazer por você. Eu não sou bom nisso' (CARVER, 2010, p. 634-635, grifo nosso).

Em seu vocabulário coloquial, o narrador fala da dimensão ocupada por catedrais que "sobem na direção do céu" e do tempo em que foi erguida, "antigamente", quando os homens queriam ficar próximos de Deus. Richard é capaz de expressar de modo mais coerente tal relação apontando como a "construção chegava a mover várias gerações até serem concluídas". O verbo usado por Richard é ouvir, ou seja, atento ao documentário, o cego compreende melhor o que escuta do que o narrador que tem acesso também às imagens. Quando o narrador fala da "importância de Deus na vida dos homens na época em que as catedrais foram erguidas", que remete a origem, delimitação e uso de uma obra arquitetônica, dentro de circunstâncias históricas, culturais e sociais especificas. Ou seja, o posicionamento tanto por parte da produção quanto da recepção da obra. Já os aspectos qualificadores operacionais, aqueles em relação às características estéticas e comunicativas da obra, no caso catedrais europeias em estilo gótico, aparecem mesclados aos elementos decorativos mencionados no trecho acerca da modalidade material.

Já os aspectos qualificadores contextuais são evidenciados naquele trecho citado anteriormente em que, ainda atento ao que ouve, o cego consegue identificar que o trecho do documentário trata de afrescos, técnica decorativa empregada nas catedrais que o narrador desconhece (CARVER, 2010, p. 633), fato 
que diz respeito à importância do conhecimento prévio para uma écfrase ser "bem sucedida".

A modalidade sensorial não foi esquecida, mas intencionalmente deixada para o final da análise. A investigação sobre o modo como os cinco sentidos afetam a produção e a recepção de uma midia é bastante relevante em uma transmidiação de arquitetura, midia capaz de ativar praticamente todos os sentidos ao mesmo tempo através de uma edificação. De acordo com o arquiteto Steen Rasmussen, "não é suficiente ver arquitetura; devemos vivenciá-la [...] devemos residir nos aposentos, sentir como nos circundam, observar como nos levam naturalmente de um para outro" (RASMUSSEN, 2002, p. 32). Assim sendo, além dos cinco sentido, a propriocepção deve ser levada em conta, isso é, as atividades cinéticas e sensório-motoras. De acordo com Elleström, seu modelo constitui um esqueleto para a investigação daquilo que acontece em uma transferência de traços midiais (ELLESTRÖM, 2017. p. 238), ou seja, não há nada a ser retirado, mas sim acrescido. Logo, para um maior entendimento do processo em que a arquitetura é transmidiada pela literatura, inclui em minha análise ${ }^{4}$ as noções de perspectiva e de corporeidade.

O termo perspectiva apresenta diferentes conotações em diferentes disciplinas. No campo da História da Arte, a "perspectiva direciona nosso olhar e organiza nossos pensamentos [...] parece controlar não somente o que é visto, mas também como ele é visto e como aquilo que é visto será descrito"5 (ELKINS, 1994, p. 212, tradução nossa), argumento que dialoga com a noção desenvolvida pelos estudos de narratologia, que sugerem que a focalização tem a capacidade de preencher lacunas dentro do enredo de objetos literários (FLUDERNIK, 2014). Como na écfrase, a perspectiva pode evidenciar a indissolúvel relação entre presença e ausência uma vez que o jogo provocado pela perspectiva permite o posicionamento do observador em lugares em que nunca esteve antes. No caso, o deslocamento dos personagens nos Estados Unidos nos anos 1980 para catedrais localizadas em países da Europa erguidas na idade média. Entretanto, apesar de todo seu empenho, como se sua própria vida dependesse daquela descrição, a focalização do narrador é restrita, como demonstrado pelo trecho a seguir:

Olhei com atenção a imagem da catedral na tevê. Como é que eu ia conseguir até mesmo começar a descreve aquilo? Mas digamos que minha vida dependesse disso. Digamos que minha vida estivesse sendo ameaçada por um maluco que dissesse que eu tinha que fazer aquilo senão...

Observei mais um pouco a catedral antes de a imagem mudar de repente outra vez para uma paisagem rural.

Não tinha jeito (CARVER, 2010, p. 634).

Já a noção de corporéité, proposta por MerleauPonty (1945), tem com o objetivo de incluir o corpo, além da mente, nos atos de percepção, experimentação e representação do mundo. Uma vez que a consciência não advém somente da mente, a noção de corporeidade tem como função garantir o papel central exercido pelo corpo no modo como experimentamos o mundo (AUSLANDER, 2008). Diferentemente da dualidade proposta pelo pensamento cartesiano, corpo e mente não podem ser dissociados, e o sujeito e objeto são uma só unidade e, desse modo, devem ser tratados como duas facetas de uma mesma entidade incorporadas no mundo. Essa noção dá suporte à premissa do arquiteto Rasmussen, de que, além de contemplada, a arquitetura precisa ser fisicamente vivenciada.

Uma vez que o narrador descreve o que vê em uma tela plana de televisão, o potencial corpóreo de uma catedral gótica não é explorado. Isso é, a transformação midiática acontece em dois níveis: o intradiegético e o extradiegético.

O primeiro nível, intradiegético, se dá a partir da coletânea de imagens acerca da arquitetura

\footnotetext{
4 Essa inclusão das noções de perspectiva e corporeidade é uma das premissas de minha tese de doutoramento (VIEIRA, 2016, p. 106113), logo foi retomada em respectivos desdobramentos da tese, entre eles o artigo "Écfrase arquitetônica: um modelo interpretativo" (VIEIRA, 2017, p. 249-251).

5 Do original: perspective directs our eyes and orders our thoughts [...] it seems to control not only what I see, but how I see and how I describe what I see.
} 
religiosa do período gótico na Europa que resulta no documentário da BBC feito para exibição na TV, em que as principais caracteristicas de catedrais góticas são descritas na narração visual, pela câmera, e verbal, por Clark, narrador do documentário. As imagens assim como os comentários do documentário são verbalizadas no conto pelo narrador de modo a desencadear uma resposta imaginativa visual na mente do personagem cego. Vale lembrar que o incomodo criado pela estética característica de documentários sobre arquitetura é o que levou o narrador a tentar preencher o silêncio de Clark, o narrador da emissão, com suas próprias palavras e impressões da construção imagética de quem filmou o programa. Além da midialidade documentário ser evocada por expressões como "tomada longa", "a câmera recuou", as similaridades na narrativa visual do documentário e na verbal do conto são evidenciadas a seguir pela sequência visual capturada a partir da reprodução do documentário na plataforma de streaming YouTube (48 min. 24 seg. $)^{6}$.

Na Figura 1, Kenneth Clark, "o inglês que narrava aquele negócio de vez em quando ficava calado e simplesmente deixava câmera passear sobre as catedrais" (CARVER, 2010, p. 633, grifo nosso), aparece no frame (46' 33') à frente de um campo a narrar uma catedral localizada à esquerda do plano de fundo. Logo nos primeiros minutos (5'42") do documentário, o espectador é apresentado a um afresco (Figura 2), que, segundo o narrador do conto, são "pinturas nas paredes [da] igreja" (CARVER, 2010, p. 633).

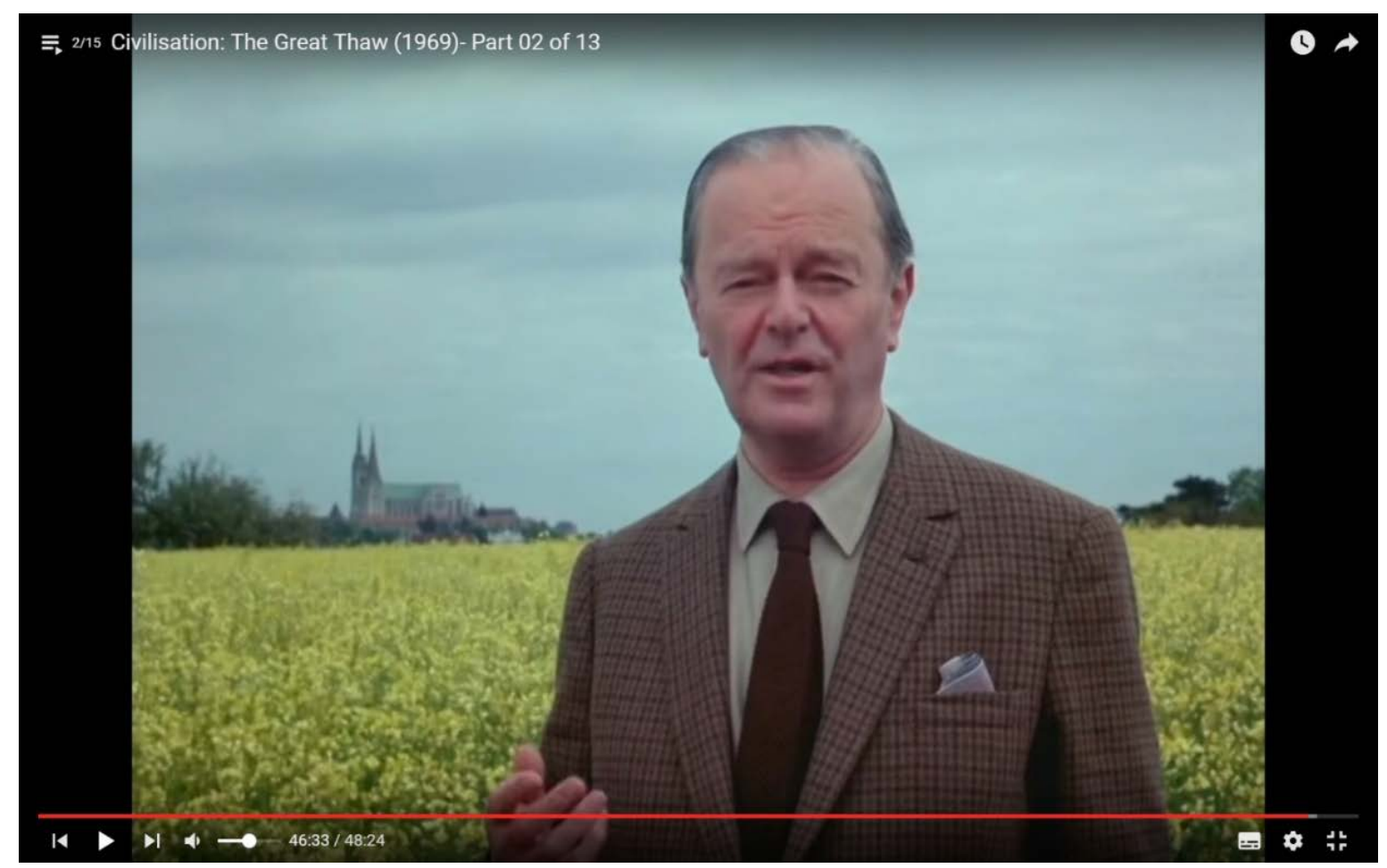

Figura 1 - Frame da reprodução do documentário Civilisation (1969), episódio 2, "The Great Thaw" Fonte: Frame de vídeo disponivel na plataforma de streaming YouTube. 


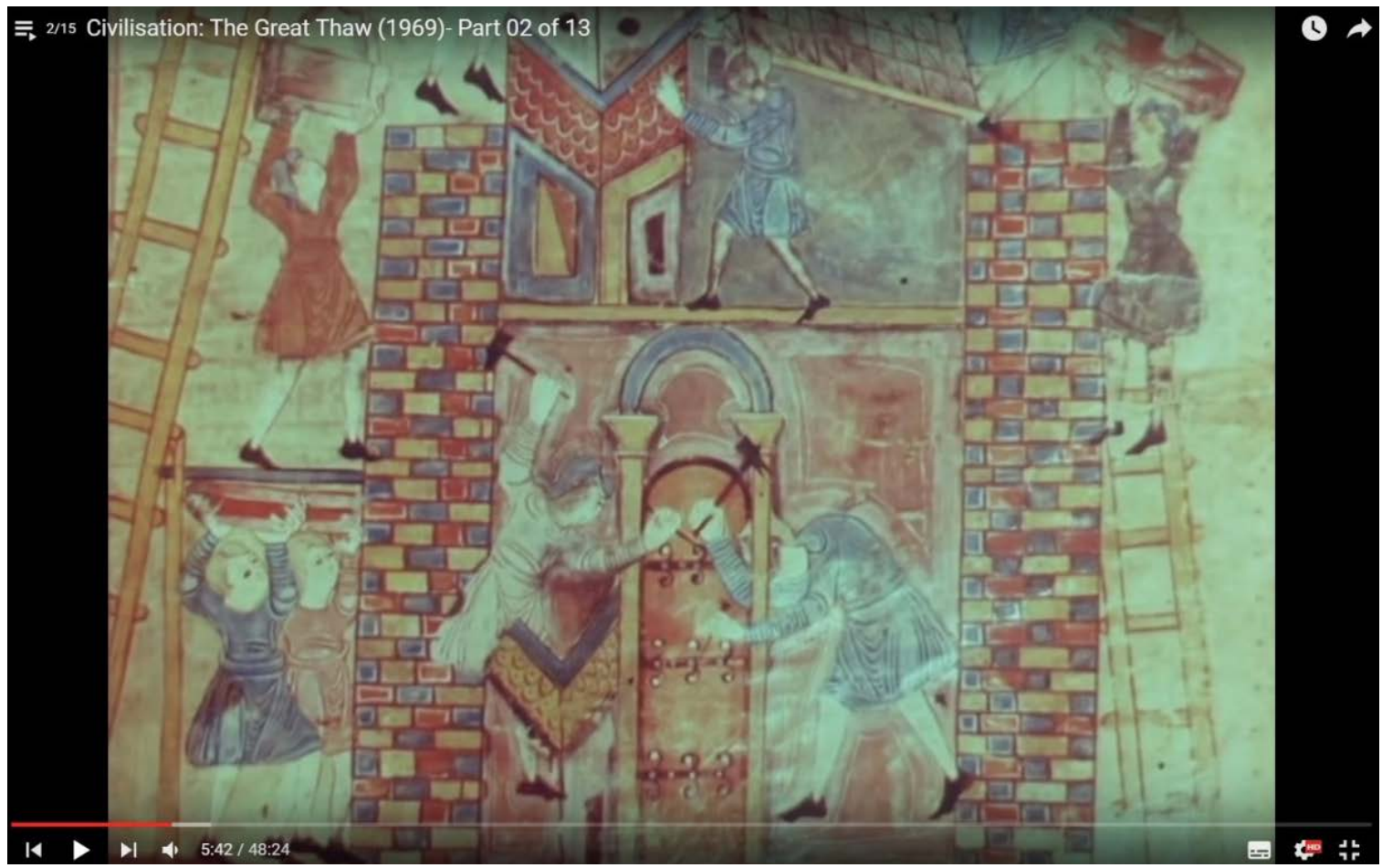

Figura 2 - Frame da reprodução do documentário Civilisation (1969), episódio 2, "The Great Thaw" Fonte: Frame de video disponivel na plataforma de streaming YouTube.

A câmera dá zoom em detalhes ornamentais típicos de catedrais góticas, como por exemplo, "as gárgulas" (Figura 3), descritas pelo narrador como "umas estátuas pequenas esculpidas para parecerem monstros," ou "demônios" (Figura 4). Mas, como evidenciado pelas Figuras 5 e 6 , "às vezes" são, segundo o narrador, "uns senhores [...] e umas senhoras" (CARVER, 2010, p. 633-634).

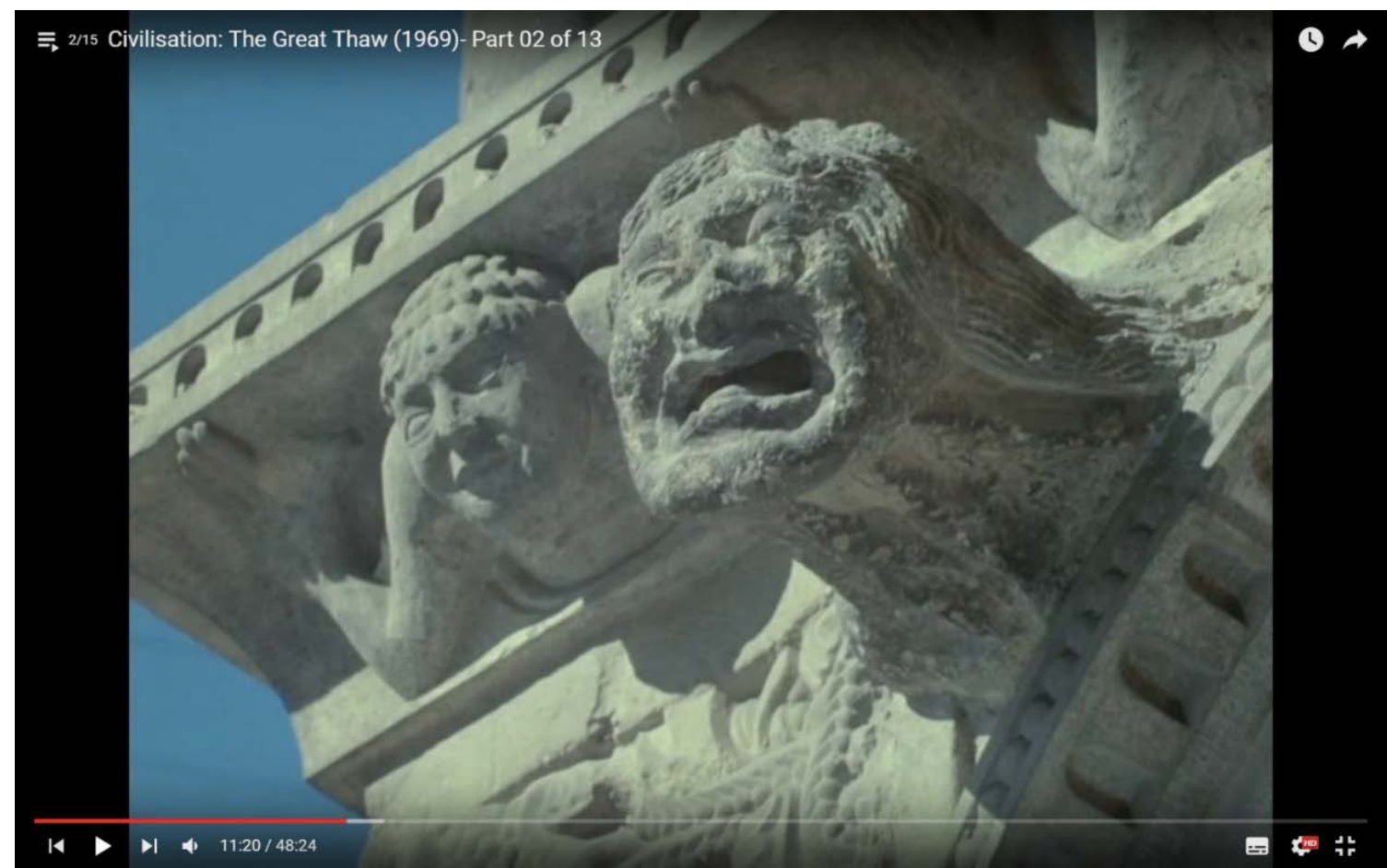

Figura 3 - Frame da reprodução do documentário Civilisation (1969), episódio 2, "The Great Thaw" Fonte: Frame de video disponivel na plataforma de streaming YouTube. 


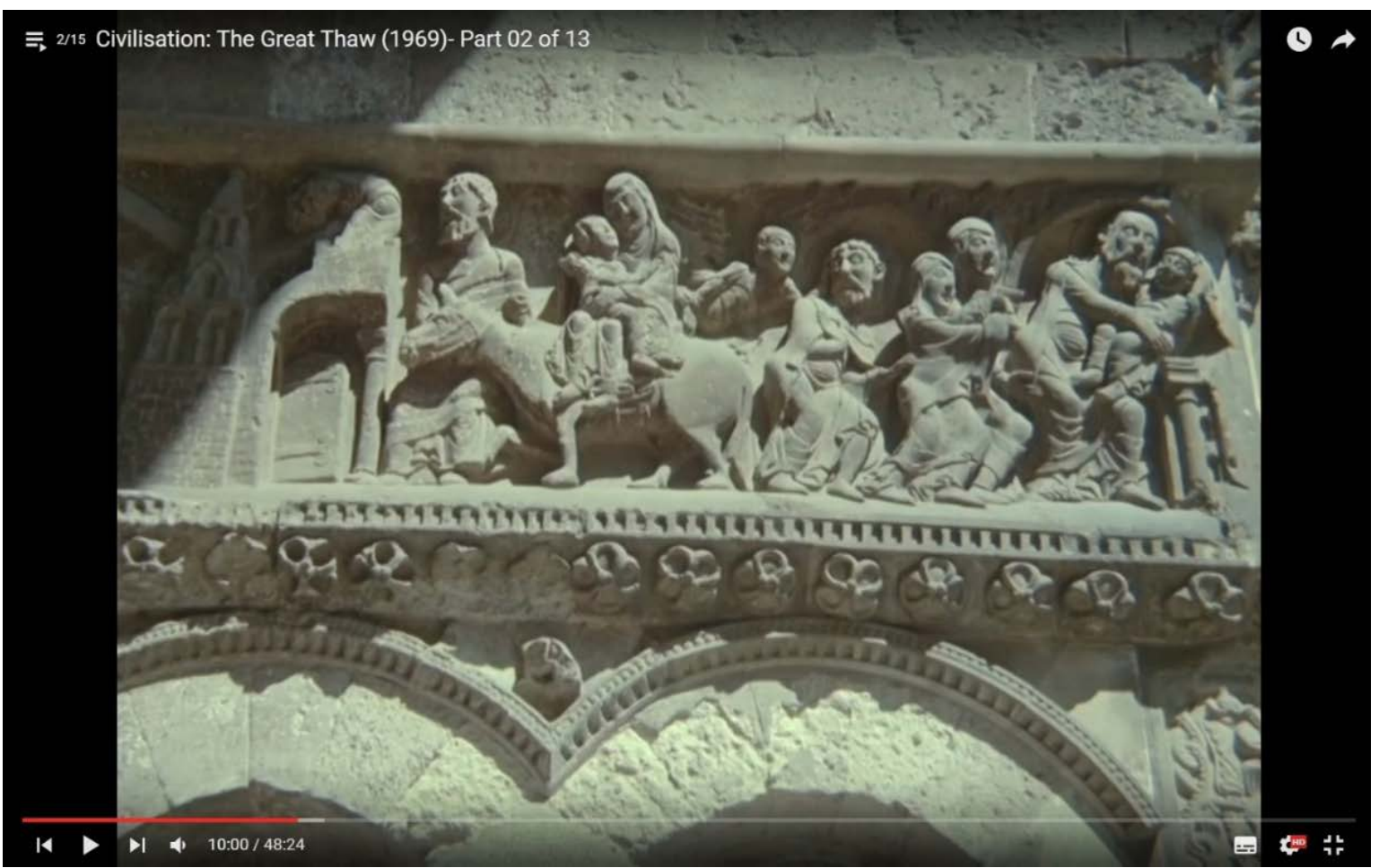

Figura 4 - Frame da reprodução do documentário Civilisation (1969), episódio 2, "The Great Thaw" Fonte: Frame de video disponivel na plataforma de streaming YouTube.

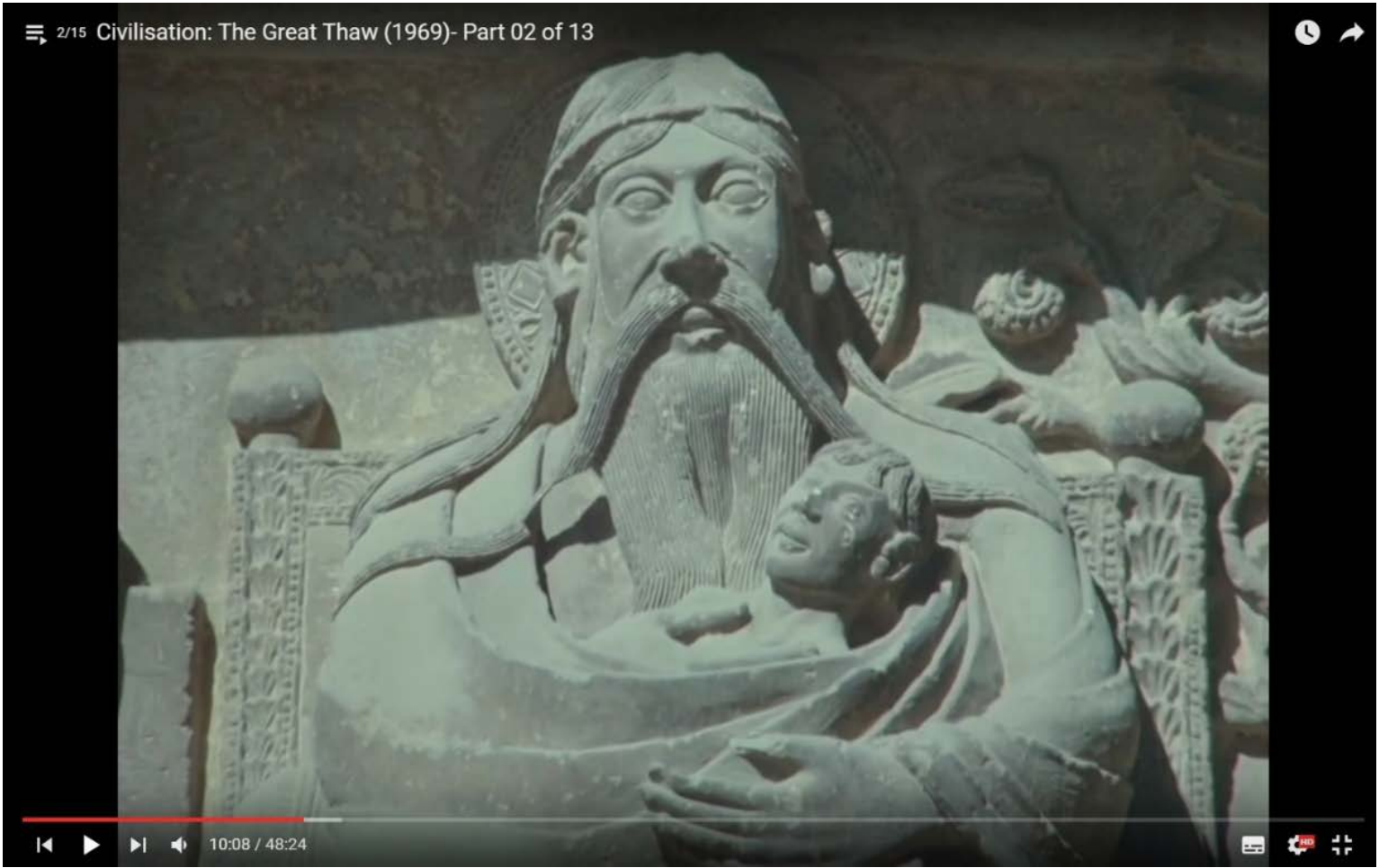

Figura 5 - Frame da reprodução do documentário Civilisation (1969), episódio 2, "The Great Thaw" Fonte: Frame de video disponivel na plataforma de streaming YouTube. 


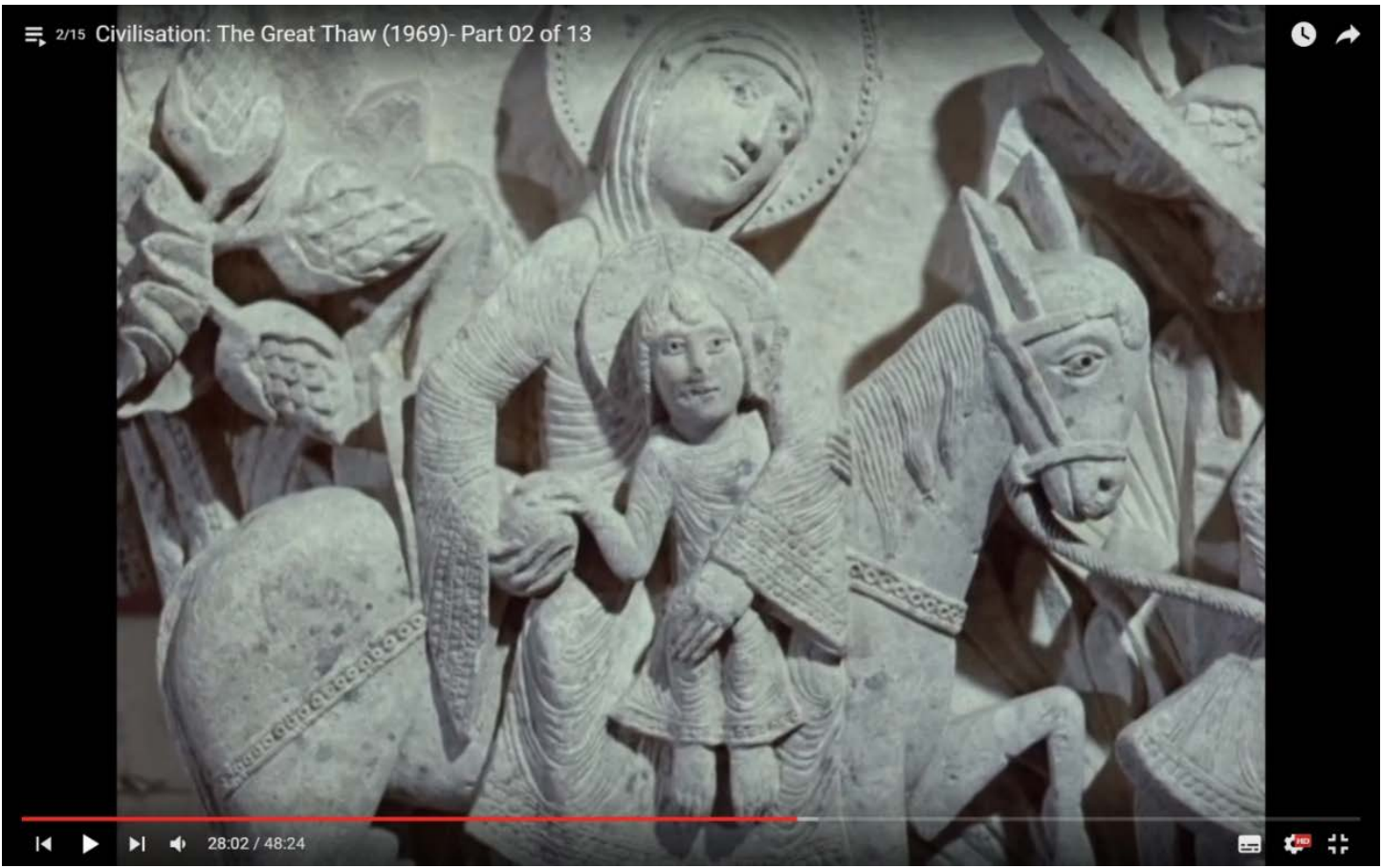

Figura 6 - Frame da reprodução do documentário Civilisation (1969), episódio 2, "The Great Thaw" Fonte: Frame de video disponivel na plataforma de streaming YouTube.

A partir de tomadas estratégicas (Figuras 7 e 8), a câmera evidencia as impressionantes dimensões das catedrais. O narrador explica que "antes de mais nada, elas são muito altas. [...] Elas sobem muito alto. Vão subindo, subindo a vida toda. Na direção do céu". Ele explica a
Robert que, como "algumas" catedrais "são tão grandes", "[...] precisam de escoras. Que ajudem a sustentar, sabe. Essas escoras são chamadas de arcobotantes", cujas formas (Figuras 8 e 9) lembram "viadutos" (CARVER, 2010, p. 634).

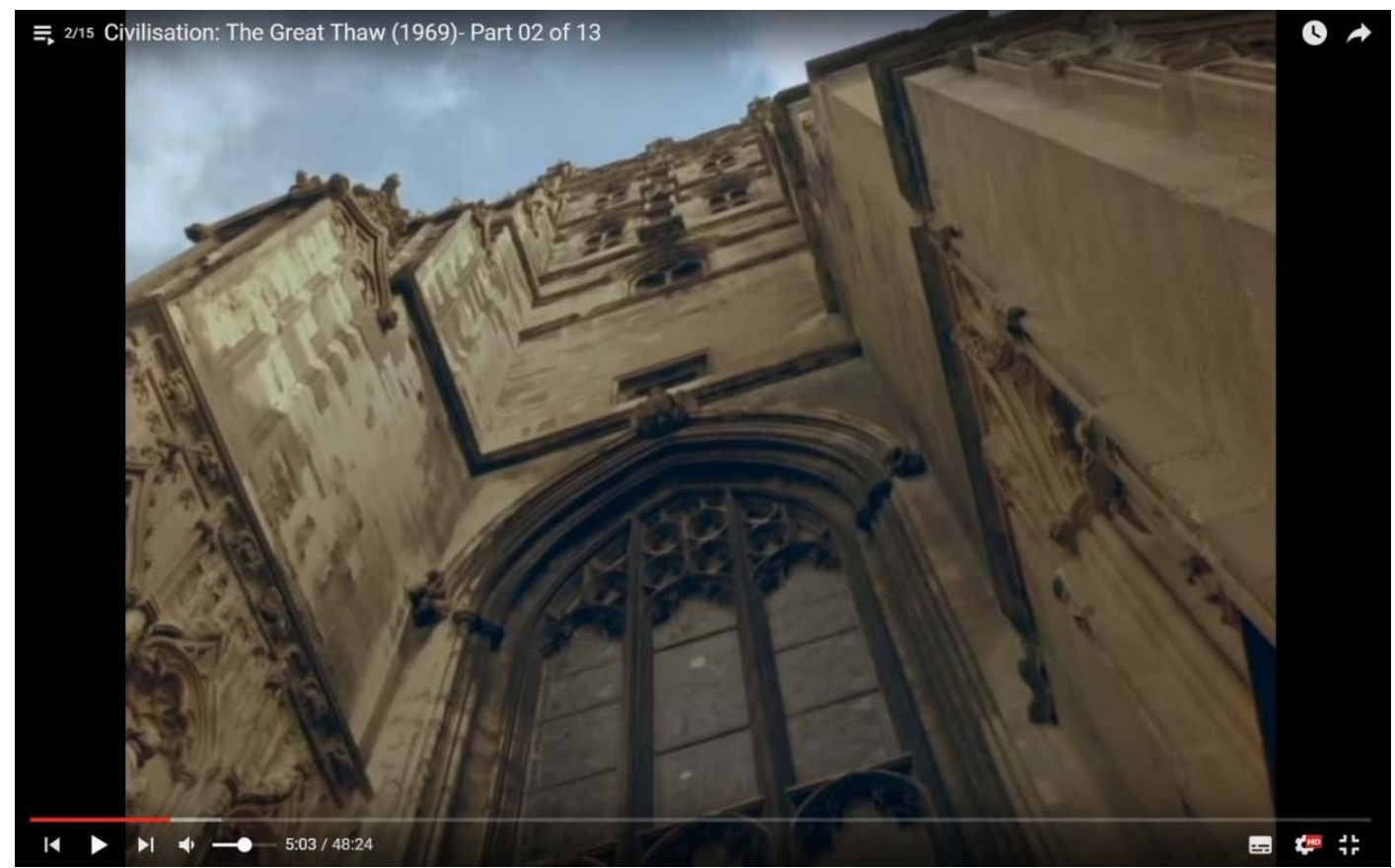

Figura 7 - Frame da reprodução do documentário Civilisation (1969), episódio 2, "The Great Thaw" Fonte: Frame de vídeo disponivel na plataforma de streaming YouTube. 


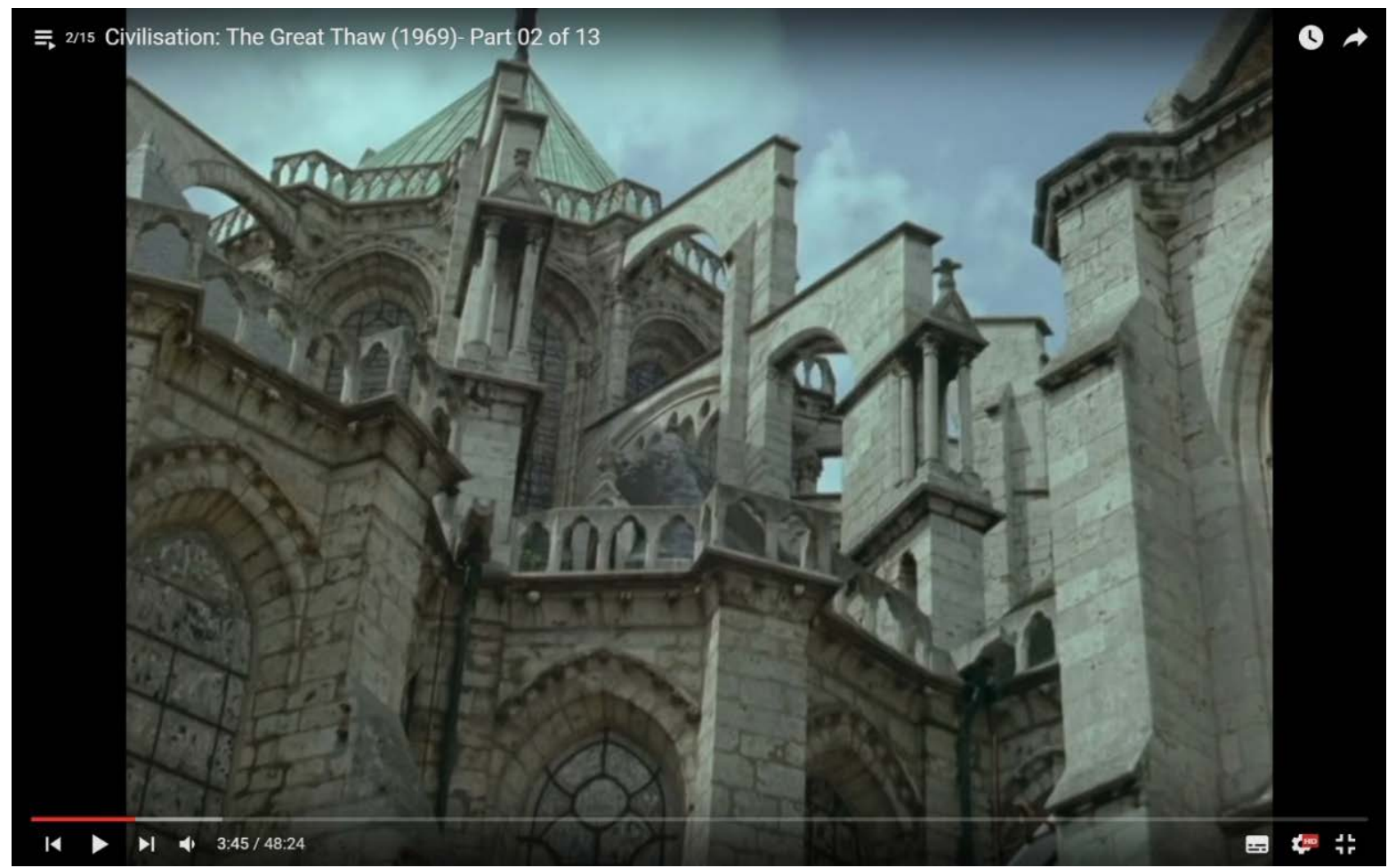

Figura 8 - Frame da reprodução do documentário Civilisation (1969), episódio 2, "The Great Thaw" Fonte: Frame de video disponivel na plataforma de streaming YouTube.

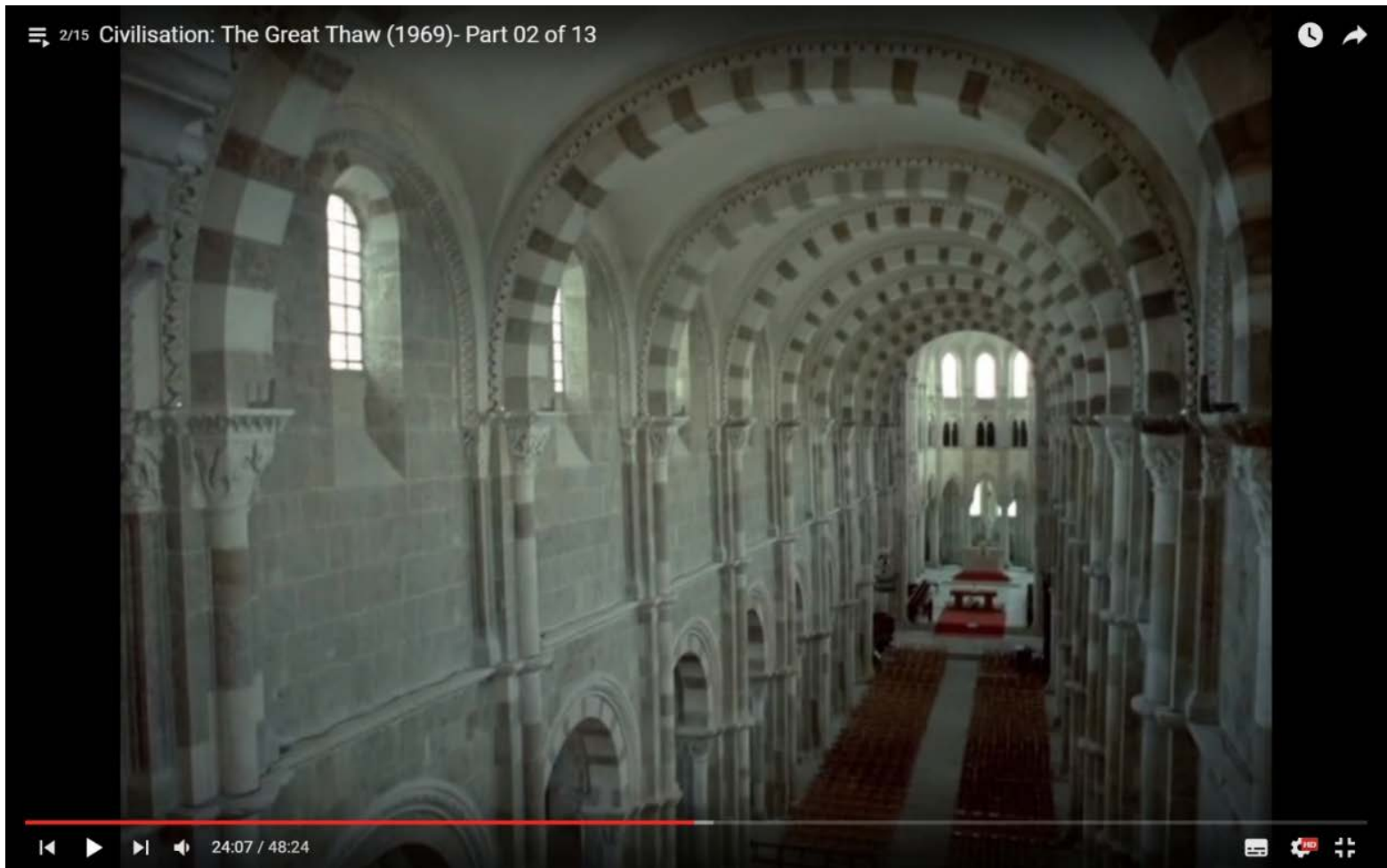

Figura 9 - Frame da reprodução do documentário Civilisation (1969), episódio 2, "The Great Thaw" Fonte: Frame de video disponivel na plataforma de streaming YouTube. 


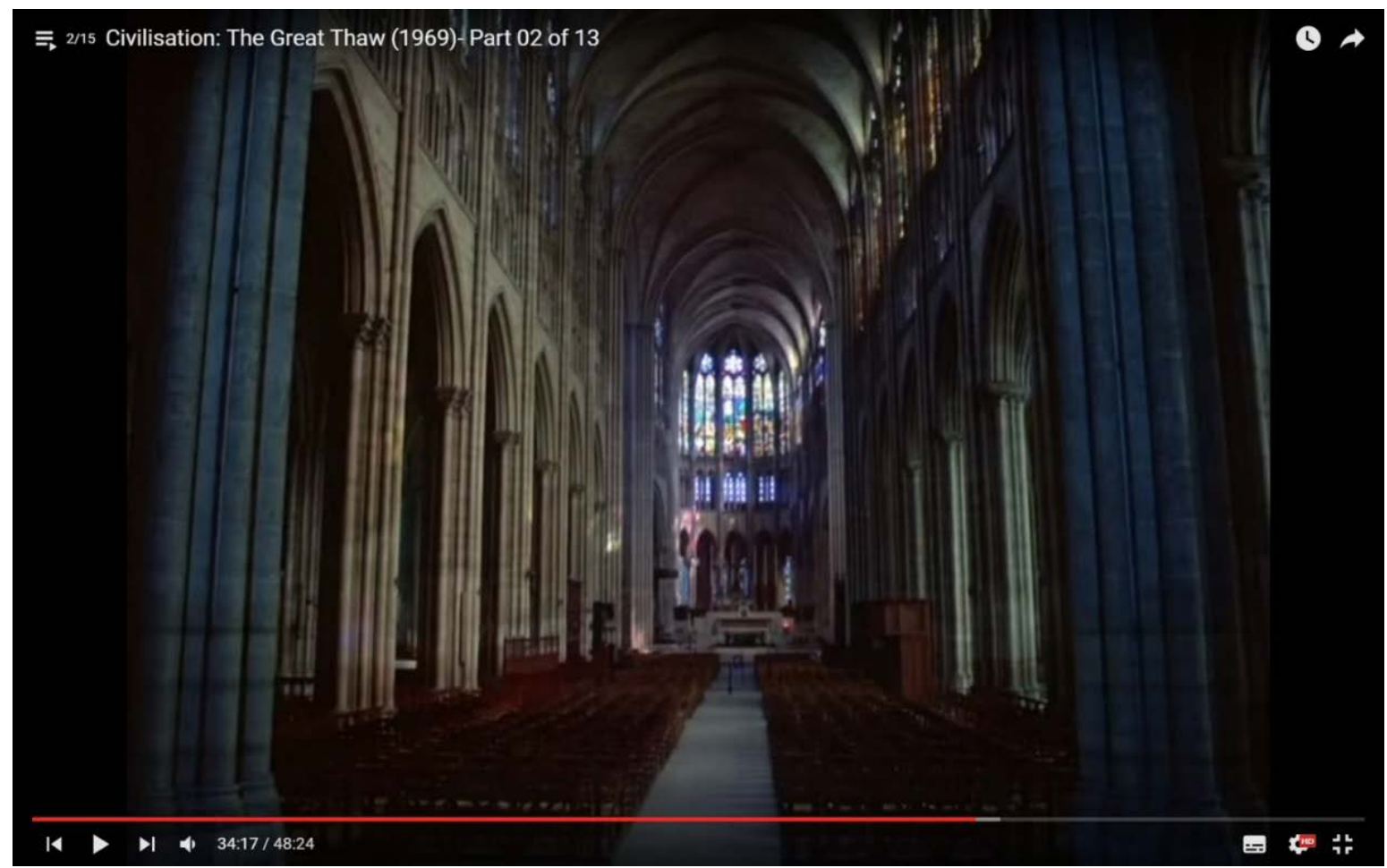

Figura 10 - Frame da reprodução do documentário Civilisation (1969), episódio 2, "The Great Thaw" Fonte: Frame de video disponivel na plataforma de streaming YouTube.

Segundo o narrador, "antigamente, na época em que os homens construiam catedrais, eles queriam ficar perto de Deus. Antigamente, Deus era uma parte importante da vida de todo mundo. Dá para ver isso pela construção das catedrais" (CARVER, 2010, p .635). Entretanto, como aquilo que o narrador vê e escuta não transmitem significado algum a ele, pois documentários sobre arquitetura "são uma coisa para a gente ficar vendo" antes de dormir, a interação não é exatamente bem-sucedida, afinal "catedrais não tem nenhum significado especial" para ele, posto que esse tipo de edificação não remete a nada, afinal é apenas "uma coisa para a gente ficar vendo na tevê tarde da noite" (CARVER, 2010, p. 635). Por sugestão de Richard, essa tentativa verbal malsucedida inspira um desenho colaborativo entre os dois personagens.

Sob efeito de álcool e maconha, o cego segura a mão do narrador que relata o que eles desenham: "uma caixa que parecia uma casa. [...] Depois um telhado em cima. Nas duas pontas do telhado, pus torres. Que doideira. [...] Não conseguia parar" (CARVER, 2010, p. 636. grifo nosso). Ironicamente, o personagem cego é a testemunha intradiegética que promove o esclarecimento epistemológico acerca da estética das catedrais góticas apresentadas pelo narrador do documentário.

O segundo nivel, extradiegético, se dá a partir da provocação verbal desencadeada pela narração do documentário e pelo desenho colaborativo resultam no conto que, por sua vez, busca uma resposta imaginativa visual, agora na mente do leitor. Ainda que o personagem narrador pontue na narrativa do conto que está relatando o que vê na telada tevê, o leitor tem acesso simultâneo a arquitetura religiosa em estilo gótico e ao documentário da rede BBC, o que intensifica sua participação no texto.

A análise da transferência de caracteristicas entre mídias dissimilares evidencia a aproximação entre o conto e o documentário, e distancia a arquitetura. Isso é, se pensarmos na noção de écfrase arquitetônica, a partir das modalidades propostas por Elleström, concordo com Bruhn que sugere que o trecho tenha fracassado, não somente pela inexistência do apelo sensório-motor, 
mas principalmente pela falta de conhecimento prévio do narrador para verbalmente expressar aquilo que vê. Entretanto, apesar de não fazer presente um monumento canônico da arquitetura religiosa medieval, o conto "Catedral" faz presente, nas palavras de Elleström, uma re-midiação da arquitetura por meio do documentário sobre catedrais góticas da rede BBC inglesa produzido para a televisão. Para mim, Carver tira proveito das catedrais para criticar a superficialidade do conhecimento passivamente adquirido pelo narrador sentado no sofá dentro de casa em frente a tela de sua tevê. Em suma, ao extrapolar suas fontes de inspiração a cânones estáticos da arte, "Catedral" trata sim da capacidade do discurso da écfrase fazer presente algo ausente. No contexto dos anos 1980 , ao criticar o estereotipo do cidadão estadunidense white trash ${ }^{7}$, a narrativa irônica de Carver reforça a ausência da arquitetura, mas intensifica a presença da mídia documentário sobre catedrais.

\section{Referências}

AUSLANDER, Philip. Theory for Peformance Studies. New York: Routledge, 2008.

BRUHN, Jørgen. What is mediality, and (How) does it matter? In: BRUHN, Jørgen. Intermediality and Narrative Literature: Medialities Matter. London: Palgrave Macmillan, 2016. p.13-40. https://doi.org/10.5007/ 2175-7968.2019v39n2p248

BRUHN, Jørgen. This beats Tapes, Doesn't it?: Women, Cathedrals, and Other Medialities in Raymond Carver's "Cathedral". In: BRUHN, Jørgen. Intermediality and Narrative Literature: Medialities Matter London: Palgrave Macmillan, 2016. p.61-82. https:// doi.org/10.1057/978-1-137-57841-9_4

CARVER, Raymond. Catedral. In: CARVER, Raymond. 68 contos de Raymond Carver, tradução Rubens Figueiredo, São Paulo: Companhia das Letras, 2010. p. 622-637. https://doi.org/10.4324/9780203498026

CARVER, Raymond. Cathedral (1981). Disponivel em: http://www.giuliotortello.it/ebook/cathedral.pdf. Acesso em: 30 out. 2019

CLARK, Kenneth (1969). The Great Thaw, episódio 2. Civilisation: A Personal View. London: BBC and John Murray. Disponivel em: https://www.youtube.com/ results?search_query=BBC+Kenneth+Clark\%27s+Civilisation. Acesso em: 30 out. 2019
CLÜVER, Claus. A new look at an old topic: ekphrasis revisited. Todas as Letras, São Paulo, v. 19, n. 1, p. 3044, 2017. https://doi.org/10.5935/1980-6914/letras. v19n1p30-44

CLÜVER, Claus. Ekphrasis and Adaptation. In: LEIT$\mathrm{CH}$, Thomas. The Oxford Handbook of Adaptation Studies. New York: Oxford U P, 2017. p. 459-476. https:// doi.org/10.1093/oxfordhb/9780199331000.013.26

ELKINS, James. The Poetics of Perspective. Ithaca: Cornell University Press, 1994

ELLESTRÖM, Lars. Media, Modality and Modes. London: Palgrave, Macmillan, 2010.

ELLESTRÖM, Lars. Media Transformation: The Transfer of Media Characteristics among Media. Houndmills: Palgrave Macmillan, 2014. https://doi. org/10.1515/ang-2016-0041

ELLESTRÖM, Lars. Midialidade: ensaios sobre comunicação, semiótica e intermidialidade. Porto Alegre: EdiPUCRS, 2017.

FLUDERNIK, Monika. Description and Perspective: the Representation of Interiors. Style, [S. l.], v. 48, n. 4, p. 461478, Winter 2014. https://doi.org/10.5325/style.48.4.461

GENTRY, Marshall; STULL, William. Conversations with Raymond Carver. Jackson and London: U P of Missisipi, 1990

GLASER, Stephanie. Space, Time and Narrative: The Literary Unfolding of Architecture. In: KRAUSE, Robert; ZEMANEK, Evi (org.). Text-Architekturen: Die Baukunst der Literatur. Berlin, Boston: De Gruyter, 2014. p. 13-30. https://doi. org/10.1515/9783110347159.13

HEMINGWAY, Ernest. Death in the Afternoon (1932). New York: Scribner Classics, 1999a.

HEMINGWAY, Ernest. Ernest Hemingway On Writing. Ed. Larry Phillips. New York: Scribner Book Company, 1999b.

MARTINS, Paulo. Uma visão perigmática sobre a écfrase. Revista Clássica, Belo Horizonte, v. 29, n. 2, p.163204, 2016. https://doi.org/10.24277/classica.v29i2.425

MIDDLETON, Peter. High visibility: Images of ethical life in The Tragic Muse and Raymond Carver's Cathedral. Rethinking History: The Journal of Theory and Practice, [S. l.], v. 2, n. 3, p. 331-8, 1998. https://doi. org/10.1080/13642529809408969

MERLEAU-PONTY, Maurice. Phénoménologie de la perception. Paris: Gallimard, 1945.

RASMUSSEN, Steen E. Arquitetura vivenciada. Tradução de Álvaro Cabral. São Paulo: Martins Fontes, 2002.

\footnotetext{
7 O termo white trash é definido como "membros da classe, especialmente no sul do pais, ou simplesmente brancos de baixa renda em geral" (tradução nossa, disponivel em: https://www.dictionary.com/browse/white-trash?s=t). Já o sitio online Urban Dictionary, chama atenção para o emprego errôneo da expressão pejorativa que define um grupo de ancestralidade anglo-saxônica que personificam conceitos de ignorância, racismo, violência e alcoolismo. Muito usado para rotular pessoas caucasianas da classe trabalhadora daquele pais (tradução nossa, disponivel em: https://www.urbandictionary.com/define.php?term=white+trash. Acesso em: 6 dez. 2019.
} 
VIEIRA, Miriam de Paiva. Écfrase: de recurso retórico na antiguidade a fenômeno midiático na contemporaneidade. Todas as Letras, São Paulo, v. 19, n. 1, p. 45-57, 2017. https://doi.org/10.5935/1980-6914/ letras.v19n1p45-57

VIEIRA, Miriam de Paiva. Écfrase arquitetônica: um modelo interpretativo. Aletria, Belo Horizonte, v. 27, n. 2, p. 241-260, 2017. https://doi.org/10.17851/23172096.27.2.241-260

Endereço para correspondência:

Miriam de Paiva Vieira

Praça Frei Orlando, 170, Centro, São João del-Rei, Minas Gerais, CEP: 36307-352 